\title{
Las relaciones comerciales entre China y Estados Unidos y el comercio de bienes industriales y agrícolas; implicaciones para México
}

\section{Introducción}

$\mathrm{A}$ 1 inicio del siglo XXI los productos fabricados en China, principalmente industriales, han venido desplazando a los hechos en México de la posición privilegiada que tenían en el mercado de Estados Unidos. Esta posición la había logrado México unos años antes con la firma del Tratado Preferencial de Comercio e Inversión signado con la Unión Americana y Canadá, conocido como Tratado de Libre Comercio de América del Norte (TLCAN).

El desplazamiento de productos hechos en México dentro del mercado de Estados Unidos se registró gracias a los precios bajos de venta de los productos chinos, a las políticas comerciales agresivas de China en los mercados externos, alianzas productivas, comerciales y de inversión chino-estadounidenses, la participación activa de China en organismos económicos internacionales, así como al estrechamien-

* Investigador del Departamento de Estudios del Pacífico, CUCSH-Universidad de Guadalajara y miembro del SNI. El autor agradece el apoyo de Gabriela López García en la recopilación y procesamiento de la información estadística de este trabajo. ORCID http:// orcid.org/0000-0002-9145-5865 to de relaciones comerciales institucionales entre ambos países. Todo ello como parte de la política de apertura del gobierno chino puesta en práctica por la dirigencia de ese país a principios de los años ochenta del siglo pasado.

En esencia, las razones del abordaje de los productos chinos al mercado de EUA las encontramos no sólo en los cambios internos de China sino en la transformación del sistema internacional, la cual creó las condiciones para que fuera posible la realización de los arreglos institucionales entre las dirigencias de ambos países. Razones de economía política, de carácter institucional y de construcción de un nuevo andamiaje internacional proporcionan el contexto general en el que se dio el acercamiento político y económico entre China y Estados Unidos.

A la par del cambio en las condiciones externas, China se embarcó en un programa de apertura hacia el exterior, el cual fue profundizándose al paso del tiempo con la experiencia acumulada. En términos económicos, ésta se aprecia con los siguientes datos: en la época de Mao Zedong no había en China una sola empresa extranjera; para 1979 ya se habían establecido alrededor de 100 empresas con capital foráneo, y al co-

MÉXICO YLACUENCADELPACÍFICO vol. 9, núm. 27 / enero-diciembre de 2006 
menzar el siglo XXI había en China 300,000 empresas extranjeras aproximadamente. Lo importante en este proceso de reestructuración productiva es que una gran parte de las empresas produjeron para los mercados internacionales. ${ }^{1}$ De manera complementaria, la política de apertura incluyó la disminución sustancial en los aranceles a una gran cantidad de bienes y servicios (Véase Hernández, 2003a: 57-68).

\section{Las relaciones comerciales entre China y Estados Unidos}

Estas relaciones datan de los primeros días de la independencia de Estados Unidos. Aunque durante el siglo XIX y principios del Xx el principal socio comercial de China fue Gran Bretaña, ya para el inicio del siglo XX (entre 1901 y 1903) el 8.5\% de las exportaciones chinas tenían como destino Estados Unidos y $10.2 \%$ de las importaciones provenían de ese país (Feuerweker, 2002). Para mediados de siglo, al finalizar la Segunda Guerra Mundial, Estados Unidos se había convertido en el principal socio comercial de China. Sin embargo, después del establecimiento de la República Popular China (RPCh) en 1949, el comercio entre ambos países comenzó a decrecer rápidamente. Estados Unidos impuso controles selectivos al comercio con China, una vez que las fuerzas comunistas fueron tomando el poder a lo largo y lo ancho del país. Los controles a las exportaciones fueron entonces gradualmente reforzadas, hasta que el embargo total fue establecido por medio del Cocom $^{2}$ al desatarse la Guerra de Corea; para 1951 prácticamente no existían relaciones comerciales entre China y Estados Unidos (Yang, 2004: 1).

Veinte años después, el reconocimiento diplomático de la RPCh y su consecuente restablecimiento del asiento en las Nacio- nes Unidas permitieron el reinicio de las relaciones comerciales entre ambos países. La visita del presidente Richard Nixon a China en 1972 creó las condiciones para reducir el control sobre las exportaciones chinas y permitirle a China ser tratada en los mismos términos que la Unión Soviética. El incremento paulatino de los intercambios comerciales entre ambos países fue inmediato.

En julio de 1979, los dos gobiernos firmaron el Tratado de Relaciones Comerciales mediante el cual cada uno se otorgó el tratamiento de nación más favorecida - conocido como de relaciones comerciales normales (NTR) - sobre una base de reciprocidad. En los años siguientes varios acuerdos específicos han sido firmados entre ambos países, incluyendo el Acuerdo de Comercio de Textiles, el Acuerdo para Evitar la Doble Tributación y el Acuerdo sobre Transporte Aéreo y Marítimo Civil. Entretanto, tres comités de trabajo conjunto fueron establecidos: el de comercio, el de ciencia y tecnología y el de asuntos económicos. En 1981, a China se le permitió el comercio de productos tecnológicamente más altos que a la Unión Soviética, y para diciembre de 1985 el Cocom adoptó la política de "línea verde" hacia China, mediante la cual se le otorgaba licencia de tratamiento preferencial a 27 categorías de los ítems bajo control de las exportaciones hacia China (Yang, 2004: 1).

Después de los incidentes de la Plaza de Tiananmen a principios del verano de 1989, Estados Unidos impuso amplias sanciones a China, incluyendo la suspensión de los intercambios oficiales y militares entre ambos gobiernos, la prohibición del financiamiento comercial de Estados Unidos y el aseguramiento a las inversiones para los proyectos relacionados con China y el embargo a las exportaciones 
a las entidades militares y policiacas de China; ello se reflejó en una disminución de $16.5 \%$ en las importaciones chinas de 1990 en relación con las de 1979; aunque al año siguiente (1991) las compras chinas a Estados Unidos se vieron compensadas con un aumento del $30.6 \%$. Desde el incidente de Tiananmen, Estados Unidos ha relacionado el estatus de nación más favorecida con los derechos humanos en China, aunque en la práctica nunca se le ha negado dicho estatus.

Los años noventa estuvieron plagados de conflictos comerciales y de tensiones políticas entre ambos países, lo cual se reflejó sobre todo en las importaciones chinas desde Estados Unidos. Sin embargo, al mismo tiempo ambas partes realizaron esfuerzos por evitar una guerra comercial. Así, en enero de 2002, Estados Unidos y China firmaron el Memorando de Entendimiento Estados Unidos-China (MOU) sobre derechos de propiedad intelectual (IPR). De conformidad con el MOU, China mejoró sus leyes sobre protección de la propiedad intelectual y se integró a las convenciones de Berna sobre Copyright y de Ginebra sobre fonogramas. Un acuerdo sobre el cumplimiento de los derechos de propiedad intelectual fue firmado entre ambos países en febrero de 1995 (Yang, 2004: 2).

En noviembre de 1999, China y Estados Unidos alcanzaron un acuerdo bilateral sobre el acceso de China a la Organización Mundial de Comercio. Este tratado creó las condiciones para que, después de 15 años de negociaciones, en diciembre de 2001 China finalmente se integrara a la OMC. ${ }^{3}$

Como se puede observar, los cambios drásticos de carácter institucional, tanto internos de China como en el contexto internacional, crearon las condiciones para que el comercio entre China y Estados Unidos creciera de manera exponencial, con el marcado desequilibrio a favor de China. En 1980, el comercio total entre ambos países había alcanzado los 4,811.27 millones de dólares, con exportaciones estadounidenses a China por 3,830.2 millones de dólares e importaciones por un valor de 981.1 millones de dólares (Yang, 1992: 387, citado por Zhang, 2001: 288). Este déficit comercial de China en su relación con Estados Unidos pasó por un breve periodo de comercio equilibrado a mediados del decenio de los ochenta y se convirtió rápidamente en un superávit creciente para China, mismo que en 2006 alcanzó la cifra de 232,548 millones de dólares.

Desde la regularización de las relaciones comerciales entre China y Estados Unidos, y en especial desde la firma del Tratado Comercial Bilateral firmado entre ambos países mediante el cual Estados Unidos aplicó un tratamiento arancelario de NTR permanente (MFN), el intercambio comercial entre ambos países ha tenido un crecimiento impresionante, puesto que pasó de 94,899.3 millones a 342,997.0 millones de dólares de comercio total entre 1999 y 2006 . Pero además, el crecimiento en las importaciones de Estados Unidos ha sido muy superior a las de las exportaciones hacia China. Como se puede apreciar en el siguiente cuadro, en 1985 las importaciones eran prácticamente iguales a las exportaciones; sin embargo, para 2006 China vendía a Estados Unidos seis veces más de lo que le compraba. Esto ha sido resultado de un incremento anual promedio de $13.7 \%$ en las exportaciones y de $23.3 \%$ en las importaciones. Para 2006 compró a Estados Unidos productos por un valor de 55,224.2 millones de dólares y vendió bienes por un valor de 287,772.8 millones de dólares, lo que le reportó un superávit de de 232,548.6 millones de dólares sólo en ese año (cuadro 1). 
Cuadro 1

Comercio de China con Estados Unidos, 1985-2006 (millones de dólares)

\begin{tabular}{lrrrrr}
\hline Año & Exportaciones & Importaciones & Saldo & \multicolumn{2}{r}{ Incremento anual \% } \\
\cline { 3 - 6 } & & & & Export. & Import \\
\hline 1985 & $3,861.7$ & $3,855.70$ & 6.0 & & \\
1986 & $4,771.0$ & $3,106.30$ & $1,664.7$ & 23.5 & -19.44 \\
1987 & $6,293.6$ & $3,497.30$ & $2,796.3$ & 31.9 & 12.59 \\
1988 & $8,510.9$ & $5,021.60$ & $3,489.3$ & 35.2 & 43.59 \\
1989 & $11,989.7$ & $5,755.40$ & $6,234.3$ & 40.9 & 14.61 \\
1990 & $15,237.4$ & $4,806.40$ & $10,431.0$ & 27.1 & -16.49 \\
1991 & $18,969.2$ & $6,278.20$ & $12,691.0$ & 24.5 & 30.62 \\
1992 & $25,727.5$ & $7,418.50$ & $18,309.0$ & 35.6 & 18.16 \\
1993 & $31,539.9$ & $8,762.90$ & $22,777.0$ & 22.6 & 18.12 \\
1994 & $38,786.8$ & $9,281.70$ & $29,505.1$ & 23.0 & 5.92 \\
1995 & $45,543.2$ & $11,753.70$ & $33,789.5$ & 17.4 & 26.63 \\
1996 & $51,512.8$ & $11,992.60$ & $39,520.2$ & 13.1 & 2.03 \\
1997 & $62,557.7$ & $12,862.20$ & $49,695.5$ & 21.4 & 7.25 \\
1998 & $71,168.6$ & $14,241.20$ & $56,927.4$ & 13.8 & 10.72 \\
1999 & $81,788.2$ & $13,111.10$ & $68,677.1$ & 14.9 & -7.94 \\
2000 & $100,018.2$ & $16,185.20$ & $83,833.0$ & 22.3 & 23.45 \\
2001 & $102,278.4$ & $19,182.30$ & $83,096.1$ & 2.3 & 18.52 \\
2002 & $125,192.6$ & $22,127.70$ & $103,064.9$ & 22.4 & 15.35 \\
2003 & $152,436.1$ & $28,367.90$ & $124,068.2$ & 21.8 & 28.20 \\
2004 & $196,682.0$ & $34,744.10$ & $161,937.9$ & 21.8 & 22.48 \\
2005 & $243,462.3$ & $41,836.50$ & $201,625.8$ & 21.8 & 20.41 \\
2006 & $287,772.8$ & $55,224.20$ & $232,548.6$ & 18.2 & 32.00 \\
\hline
\end{tabular}

Fuente: U.S. Census Bureau, Foreign Trade Division,

Actualmente los productos hechos en China prácticamente dominan el mercado estadounidense de productos manufacturados, una realidad visible en cualquier tienda departamental y en la vida diaria de las familias estadounidenses. Una mirada cercana a los productos importados de China muestra que tales importaciones compiten con las fábricas estadounidenses de productos industriales. Juguetes, calzado, ropa, aparatos electrónicos y otros productos de la industria ligera se mantienen entre los principales productos de importación. Pero además, productos como autopartes, plásticos, productos electrónicos de uso industrial, partes de computadora y otros productos de manufactura avanzada están creciendo rápidamente en el mercado de Estados Unidos (The China Business Forum, 2005a: 3).

Otra razón importante del aumento en el déficit del comercio bilateral ChinaEstados Unidos está en los patrones de comercio, en las corrientes de inversión extranjera directa y en la estructura de producción dentro del Este de Asia. Empresas de Japón, Corea del Sur, Taiwán y de otras economías de la región están manufacturando en sus países los componentes más sofisticados. Estos productos son enviados a China; ahí adquieren las partes menos complejas y de bajo costo, para luego ensamblar los bienes finales que son enviados directamente al mercado internacional, incluyendo Estados Unidos y Europa. El resultado es que el Este de Asia ha logrado convertir en realidad el sueño del TLCAN: formar un centro manufacturero regional que aproveche las ventajas productivas de cada una de las economías (The China Business Forum, 2005b).

Pero la capacidad productiva de China y su propio mercado son un factor de atracción para empresas de otros continentes. El mercado chino - el quinto a nivel mundial- es tan grande que empresas como General Motors y Caterpillar han estado muy proclives a trasladar su producción a China, en lugar de otros países en desarrollo. Actualmente ambas empresas ya realizan parte de su producción en este país (The China Business Forum, 2005b).

La plataforma de trabajo de esta eficiente maquinaria regional de exportación hacia los mercados internacionales se encuentra en las reglas comunes de la OMC, a la cual China se integró en 2001. Estas reglas hacen muy difícil para el resto de los países, incluyendo Estados Unidos, imponer límites de manera unilateral a las importaciones desde China y utilizar la gran cantidad de oferta de mano de obra barata del país. Sólo en dos tipos de bienes las reglas de la OMC permiten restricciones: productos agrícolas y textiles. Y en el caso de estos últimos existe el compromiso por parte de Estados Unidos de eliminar las salvaguardas para 2009, como se puede apreciar en el siguiente recuadro. 


\section{Hitos en las relaciones comerciales entre China y Estados Unidos}

2001 (11 de diciembre): ingreso de China a la Organización Mundial del Comercio. 2003: $100 \%$ de inversión extranjera en facilidades turísticas (hoteles).

2004: eliminación en las restricciones para distribuir bienes importados.

2005: completada la mayoría de las reducciones arancelarias y eliminadas las restricciones geográficas a los teléfonos celulares. 2006: eliminación de la mayoría de las cuotas. Expectativa del cumplimiento total del acuerdo comercial EUA-China.

2007: reducción arancelaria a 10\% en el sector automotriz.

2009: eliminación de las salvaguardas a los textiles por parte de EUA.

2013: fecha final para la protección por parte del Congreso de EUA contra el "rápido incremento en las importaciones".

La "incapacidad" de Estados Unidos para vender a China es resultado de diversas limitaciones de carácter institucional, algunas de las cuales han sido autoimpuestas por los propios estadounidenses, tales como las restricciones a las visas impuestas desde septiembre de 2001 y los límites a las exportaciones de tecnología con potencial de aplicaciones militares y no civiles en general (The China Business Forum, 2005b).

Otras limitaciones a las ventas estadounidenses a China son resultado de las políticas del gobierno chino, como el tope por 20,000 millones de dólares a las compras gubernamentales y la paridad fija del yuan frente al dólar que China mantuvo durante dos decenios.

La estructura comercial entre ambos países, caracterizada por el marcado déficit de Estados Unidos, ha sido una fuente constante de tensión entre ambos países, tal como da cuenta de ello la prensa internacional. Desde la perspectiva oficial de China, Estados Unidos "debería dar más juego a su ventaja competitiva, fomentar la confianza mutua y rebajar los controles sobre las exportaciones (a China) con el fin de impulsar la competitividad de compañías estadounidenses" y con ello reducir su déficit comercial con China. Esto lo señaló recientemente la viceministra $\mathrm{Wu}$ Yi en un artículo para la versión asiática del Wall Street Journal. Por otra parte, el China Daily comenta que la administración estadounidense ha adoptado una política de estricto control en las exportaciones de productos de alta tecnología a China por "razones de seguridad", lo cual ha limitado las exportaciones estadounidenses a China. ${ }^{4}$ Para eliminar esta inquietud de Estados Unidos, China ha insistido en que las transferencias tecnológicas a las empresas chinas estén acompañadas de acuerdos específicos de importación para cualquier producto, desde autos hasta software de cómputo.

Con el fin de reducir el marcado superávit comercial de China, una buena parte de la comunidad internacional ha presionado a ese país para que permita el deslizamiento más amplio de su moneda, de tal manera que se dé una revaluación más rápida del yuan. Como respuesta a estas presiones internacionales (en especial de Estados Unidos y de la Unión Europea), China anunció el pasado 21 de mayo que permitirá que la tasa de oscilación de su moneda respecto a la estadounidense aumente del 0.3 al 0.5\%. Además, el Banco Popular de China (PBOC) aumentó los tipos de interés y el coeficiente de caja en los bancos (The China Business Forum, 2007).

\section{Comercio de productos industriales}

En cuanto a productos industriales, los cuadros 2 y 3 que se presentan a continuación dan cuenta del enorme desequilibrio comercial dentro de este sector. Sólo en

MÉXICO YLACUENCADELPACÍFICO vol. 9, núm. 27 / enero-diciembre de 2006 
maquinaria y equipo eléctrico, mientras en 2005 China exportó a Estados Unidos productos por valor de 53,009.7 millones de dólares, importó de ese país 6,850.5 millones de este mismo tipo de bienes. Desequilibrio similar se encuentra en el caso de equipo de generación de energía, para no mencionar los casos de juguetes, muebles, ropa y calzado que aparecen en la lista de los principales productos chinos exportados a Estados Unidos y no aparecen en la lista de los productos importados de China desde ese país. Con excepción de algunos productos como aviones Boeing, plantas de energía de General Electric, partes de locomotoras y motores de avión, que mostraron aumentos importantes en las exportaciones estadounidenses hacia China, el resto de los bienes industriales tuvieron aumentos superiores en la importaciones de Estados Unidos desde China (The China Business Forum, 2005b).

\section{Cuadro 2}

Estados Unidos: principales productos industriales exportados a China, 2005 (Millones de dólares)

\begin{tabular}{llrr}
\hline$H S$ & Descripción & Valor & Incremento \%* \\
\hline 85 & Maquinaria y equipo eléctrico & $6,850.5$ & 13 \\
84 & Equipo de generación de energía & $6,357.2$ & 2.1 \\
88 & Equipo aéreo y espacial & $4,381.5$ & 124.6 \\
90 & Equipo óptico y médico & $2,396.7$ & 15.3 \\
39 & Plásticos y artículos de plástico & $2,258.9$ & 26 \\
28,29 & Químicos orgánicos e inorgánicos & $1,961.6$ & 3.2 \\
72,73 & Hierro y acero & $1,864.7$ & 40.1 \\
\hline
\end{tabular}

*En relación con el año anterior.

Fuente: US International Trade Commission; US Department of Commerce; US Bureau of the Census.

Tomado de The US-China Business Council, US-China Trade Statistics and China's World Trade Statistics.

\section{Cuadro 3}

Estados Unidos: principales productos industriales importados de China, 2005 (Millones de dólares)

\begin{tabular}{llcr}
\hline$H S$ & Descripción & Valor & Aumento \\
\hline 85 & Maquinaria y equipo eléctrico & $53,009.7$ & 32.2 \\
84 & Equipo de generación de energía & $52,732.7$ & 20.2 \\
95 & Juguetes y juegos & $19,140.7$ & 11.1 \\
94 & Muebles & $17,054.4$ & 18.3 \\
61,62 & Ropa & $16,807.9$ & 56.8 \\
64 & Calzado y sus partes & $12,721.3$ & 12.1 \\
72,73 & Hierro y acero & $7,414.8$ & 31 \\
39 & Plásticos y artículos de plástico & $6,639.5$ & 27.8 \\
42 & Pieles y artículos para viaje & $6,258.8$ & 9.4 \\
87 & Vehículos y sus partes, diferentes a los de ferrocarril & & \\
\hline
\end{tabular}

*En relación con el año anterior.

Fuente: US International Trade Commission; US Department of Commerce; US Bureau of the Census. Tomado de The US-China Business Council, US-China Trade Statistics and China's World Trade Statistics. 


\section{Comercio agrícola}

La relación comercial de productos agrícolas entre China y Estados Unidos es marcadamente deficitaria para China. De hecho, los productores agrícolas de Estados Unidos han visto al mercado chino como uno de los más promisorios. Aunque, por otro lado, China ha insistido en una política de seguridad alimentaria, insistiendo en mantener un elevado nivel de autosuficiencia interna, aun granos básicos donde la dotación de factores podría hacer econonómicamente inviable para China la producción interna de varios productos (Véase Hernández, 2003b: 115-125).

Desde que China se adhirió a la OMC en 2001, el comercio agrícola entre ambos países se ha incrementado de manera muy significativa. Las exportaciones agrícolas de Estados Unidos a China aumentaron en $270 \%$ de 2001 a 2005 al pasar de 1,938.7 a 5,233.2 millones de dólares en ese periodo; por su parte, las exportaciones agrícolas de China a Estados Unidos tuvieron un incremento de $229 \%$ al pasar de 816.2 a 1,871.8 millones de dólares de 2001 a 2005 (cuadro 4).

El mayor incremento de las exportaciones agrícolas de Estados Unidos a China, que las de China a Estados Unidos, propiciaron un aumento en el déficit del comercio agrícola chino; éste pasó de 1,122 millones de dólares en 2001 a 3,927 millones de dólares en 2004, aunque bajó ligeramente a 3,361 millones en 2005.

Por lo que respecta a la proporción del comercio agrícola entre China y Estados Unidos en el total del comercio, ésta aumentó de 4.5 a $17.2 \%$ de acuerdo con el Ministerio de Agricultura de China. Estados Unidos ha comenzado a ser una de las principales fuentes de importación de productos agrícolas para China.

Aunque las importaciones de productos hortofrutícolas de Estados Unidos au-

Cuadro 4

Exportaciones agrícolas de Estados Unidos a China

(Miles de dólares)

\begin{tabular}{lrrrrr}
\hline & 2001 & 2002 & 2003 & 2004 & 2005 \\
\hline Total & $1,938,690$ & $2,067,762$ & $5,016,684$ & $5,542,444$ & $5,233,180$ \\
Cereales & 2,214 & 1,811 & 2,600 & 4,580 & 4,550 \\
Soya & $1,012,486$ & 995,837 & $2,888,772$ & $2,328,762$ & $2,248,983$ \\
Frutas & 33,937 & 35,873 & 52,449 & 65,711 & 109,143 \\
Hortalizas & 161,487 & 171,378 & 296,443 & 355,390 & 314,000 \\
\hline
\end{tabular}

Importaciones agrícolas de Estados Unidos desde China (miles de dólares)

\begin{tabular}{lrrrrr}
\hline & 2,001 & 2,002 & 2,003 & 2,004 & 2,005 \\
\hline Total & 816,238 & $1,001,695$ & $1,287,600$ & $1,615,150$ & $1,871,829$ \\
Cereales & 65 & 48 & 128 & 227 & 275 \\
Soya & 908 & 1,831 & 1,788 & 14,234 & 21,212 \\
Frutas & 111,710 & 162,144 & 264,889 & 356,670 & 418,821 \\
Hortalizas & 388,045 & 505,079 & 659,331 & 865,288 & $1,001,157$ \\
\hline
\end{tabular}

Fuente: Department of Commerce, U.S. Census Bureau, Foreign Trade Statistics (24/01/07). 
mentaron de 16,000 a 18,000 millones de dólares y los productos de origen animal de 7,000 a 9,000 millones, China se queja de que algunos productos chinos con ventajas comparativas, como las peras y las manzanas, no tienen acceso al mercado de Estados Unidos (The China Business Forum, 2005c).

En palabras de A. Ellen Terpstra, del Departamento de Agricultura de Estados Unidos, China es la segunda economía más grande del mundo, con un vasto y creciente mercado para los productos agrícolas de Estados Unidos. Entre los más recientes éxitos comerciales de Estados Unidos de los últimos años sobresale el comercio agrícola con China. Actualmente China es el mercado número uno de soya, algodón, pieles y cueros. Asimismo, ocupa el sexto rango en las exportaciones de trigo (USDA Foreign Agricultural Service, 2005).

De acuerdo con su punto de vista, el consumo agrícola global de China, así como las importaciones, tendrán un gran incremento en los próximos años. De hecho, la consultoría económica Global Insight proyecta que el consumo alimentario al detalle podría expandirse en 25,000 millones de dólares anuales para el año 2020, lo que podría convertir a este mercado en el de más rápido crecimiento a nivel mundial.

China es ahora el cuarto mayor importador agrícola del mundo, con importaciones por valor de 26,000 millones de dólares en 2004. El incremento de las exportaciones de Estados Unidos a China pasó de 1,800 millones de dólares aproximadamente en el año fiscal de 2002, a 6,100 millones en 2004. Esto se explica, en buena medida, por la disminución de los aranceles agrícolas promedio de 31 a 14\% comprometida en el marco de los compromisos adquiridos con la OMC (USDA Foreign Agricultural Service, 2005: 2).
China es ahora el quinto mayor mercado de exportación agrícola para Estados Unidos, sólo después de Canadá, México, Japón y la Unión Europea. Pero se espera que el grueso de las mercancías continúe dominando el panorama de las exportaciones de Estados Unidos en un futuro previsible.

El aumento en el ingreso de los 350 millones de familias chinas, de la cuales aproximadamente 50 millones son consideradas de clase media, ha estimulado fuertemente la demanda de productos agrícolas de Estados Unidos. Se considera que para el año 2020 China tendrá 500 millones de familias, de las cuales $45 \%$ o sea 220 millones de consumidores dispondrán de un ingreso suficiente para adquirir la mayoría de los productos exportados por Estados Unidos (USDA Foreign Agricultural Service, 2005: 2).

\section{Implicaciones para México}

En el caso de México, como ha sido ampliamente estudiado, el instrumento que propició el incremento de la relación comercial con Estados Unidos fue la firma del Tratado de Libre Comercio de América del Norte. Pero las ventajas de la apertura del mercado de Estados Unidos han sido efímeras, puesto que este país continúa abriendo sus mercados a otras regiones y países. El caso típico es el de China, con el cual si bien no ha firmado un TLC, las reglas de operación de la Organización Mundial del Comercio y los acuerdos previos firmados entre ambos países han abierto el mercado de Estados Unidos para los productos chinos en condiciones bastante favorables. El tratado comercial firmado entre China y Estados Unidos posee muchos de los elementos de un TLC. 
Esta circunstancia ha permitido que las importaciones estadounidenses de productos chinos se hayan incrementado mucho más rápido que las de sus otros socios comerciales más importantes. Como se aprecia en las siguientes gráficas, entre 2000 y 2005, mientras las importaciones de Estados Unidos aumentaron en 143.6\% de China, de México aumentaron 25.2\% y de Canadá 25.6\%. Las importaciones estadounidenses de Japón disminuyeron en $15.1 \%$. Durante el mismo periodo Estados Unidos aumentó sus exportaciones en $157.4 \%$ a China, en $7.4 \%$ a México y en $19.8 \%$ a Canadá; mientras que las exportaciones a Japón disminuyeron en 5.6\% durante el mismo periodo.

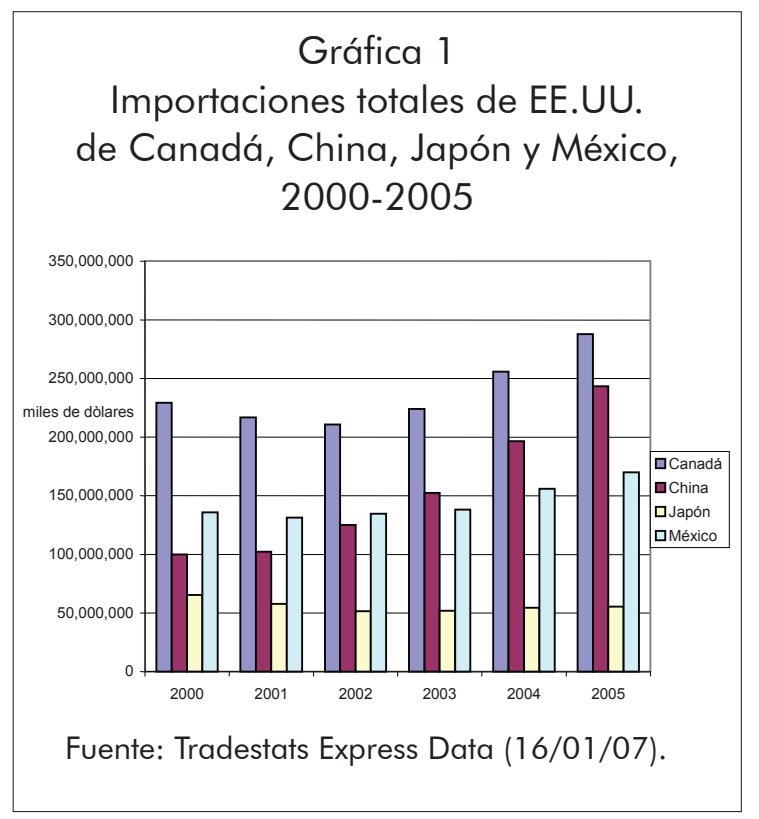

En cuanto a la competencia por el mercado de Estados Unidos, en la gráfica siguiente podemos apreciar que en 2002 China superó a México en el valor de las exportaciones al mercado estadounidense, y desde entonces el crecimiento en las ventas de productos hechos en China al mercado de Estados Unidos ha seguido en aumento.

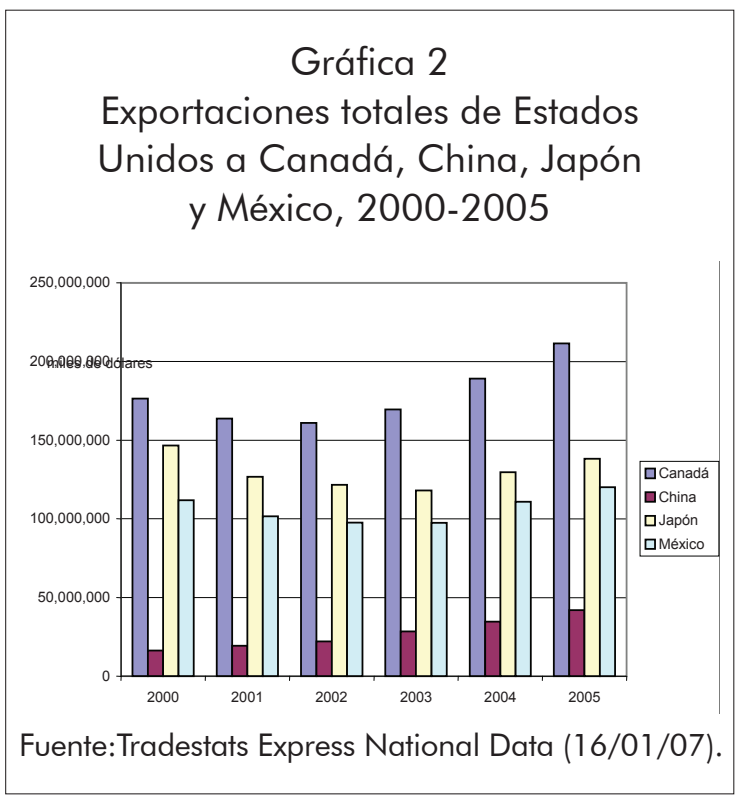

\section{Productos industriales}

En cuanto a productos industriales, la pérdida del mercado de Estados Unidos se percibe en cada uno de los principales rubros del comercio de México con ese país. A continuación en el cuadro 5 se muestra en detalle el año en que las ventas de productos hechos en china superaron a los bienes hechos en México, así como el crecimiento registrado entre 2000 y 2005. En cuanto al comercio total, en 2003, mientras China colocó en el mercado de EUA productos por valor de 152.4 mil millones de dólares, México vendió en ese mercado productos por valor de 138.1 mil millones de dólares, superando así por primera vez a nuestro país. Además en el lustro 20002005 el crecimiento de las exportaciones de China fue de $143.3 \%$, mientras que en el caso de México el aumento en las ventas fue de $25.2 \%$ en el mismo periodo. En rubros específicos, como maquinaria (HS 84 y HS 85) en 2002 y 2004 las ventas de productos hechos en China superaron a los hechos en México. Casos similares son los de prendas de vestir (HS 61), artículos varios de metal (HS 83) y artículos de hule 
$\underline{\text { Análisis }}$

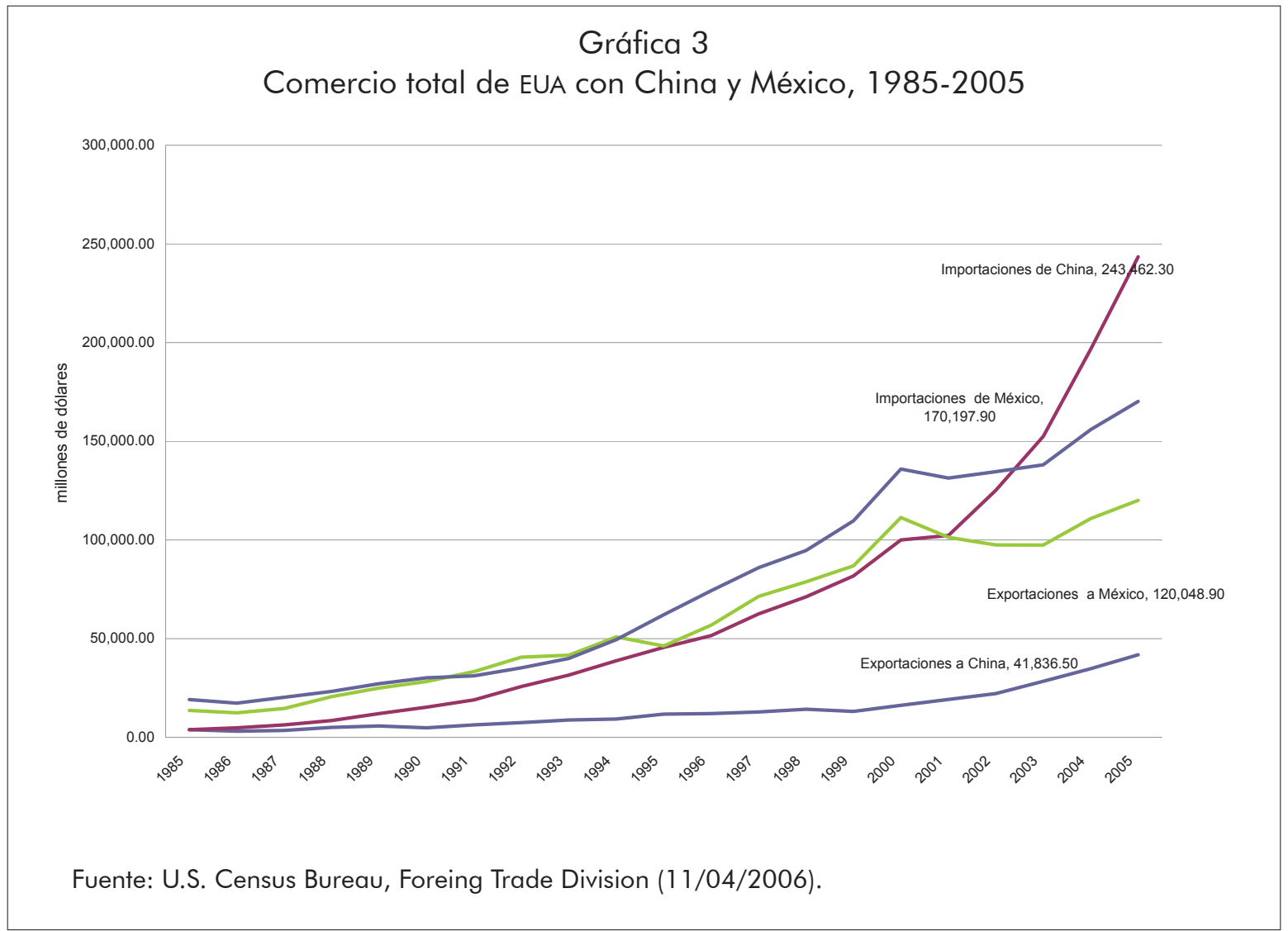

(HS 40). En otros casos, como se muestra en el mismo cuadro, los productos hechos en China ya superaban a los hechos en México desde antes de este lapso que ahora se analiza.

\section{Productos agrícolas}

En cuanto a bienes agrícolas, la situación y las características son diferentes que las de los productos industriales. Tanto China como México son importadores netos de granos básicos y son exportadores netos de frutas y hortalizas. En este sentido, las importaciones chinas de granos inciden de manera indirecta, pero importante, sobre los precios y las condiciones de las importaciones mexicanas, lo mismo que en el caso de los productos agrícolas intensi- vos en manos de obra en los que China y México compiten por el mercado de Estados Unidos.

Como se aprecia en los cuadros siguientes, Estados Unidos ha mantenido un superávit comercial agrícola tanto con México como con China. Sólo en 2005 el superávit con México fue de 1,098.7 millones de dólares y con China alcanzó la cifra de 3,361.3 millones de dólares. Otro aspecto significativo es que tanto en el caso de México como en el de China los granos y las oleaginosas son los principales productos de exportación de Estados Unidos a ambos países. Asimismo, Estados Unidos importa de México y China principalmente frutas y hortalizas. En estos productos, si bien México supera con mucho a China en el valor de las exportaciones a Estados Uni- 


\section{Cuadro 5}

Exportaciones de Mexico y China a Estados Unidos 2000-2005 (millones de dólares)

\begin{tabular}{|c|c|c|c|c|c|c|c|}
\hline & 2000 & 2001 & 2002 & 2003 & 2004 & 2005 & $\begin{array}{r}\text { Incremento } \\
2005 / 2000\end{array}$ \\
\hline \multicolumn{8}{|l|}{ Total } \\
\hline China & 100,063 & 102,280 & 125,168 & 152,379 & 196,699 & 243,462 & 143.3 \\
\hline Mexico & 135,911 & 131,433 & 134,732 & 138,073 & 155,843 & 170,198 & 25.2 \\
\hline \multicolumn{8}{|c|}{ HS 85. Maquinaria electrica etc., equipos de sonido, equipos de T.V.; sus partes } \\
\hline China & 19,564 & 19,728 & 24,404 & 28,790 & 40,176 & 53,100 & 171.4 \\
\hline Mexico & 35,778 & 33,409 & 32,707 & 32,888 & 37,408 & 39,838 & 11.3 \\
\hline \multicolumn{8}{|c|}{ HS 84. Reactores nucleares, boilers, maquinaria, etc.; partes para } \\
\hline China & 13,406 & 13,718 & 20,215 & 29,902 & 43,853 & 52,733 & 293.4 \\
\hline Mexico & 17,046 & 18,217 & 17,806 & 17,381 & 20,036 & 21,411 & 25.6 \\
\hline \multicolumn{8}{|c|}{ HS 95. Juguetes, Juegos y equipo deportivo; partes y accesorios } \\
\hline China & 12,382 & 12,215 & 14,441 & 16,105 & 17,224 & 19,141 & 54.6 \\
\hline Mexico & 667 & 779 & 1,220 & 597 & 539 & 544 & -18.5 \\
\hline \multicolumn{8}{|c|}{ HS 94. Muebles, ropa de cama, etc; lamparas refractarias, ext.; bd prefabricado } \\
\hline China & 7,202 & 7,491 & 9,923 & 11,824 & 14,422 & 17,055 & 136.8 \\
\hline Mexico & 3,821 & 3,914 & 4,544 & 5,058 & 5,147 & 5,263 & 37.8 \\
\hline \multicolumn{8}{|c|}{ HS 64. Calzado, polainas etc. y sus partes } \\
\hline China & 9,195 & 9,758 & 10,227 & 10,565 & 11,351 & 12,721 & 38.4 \\
\hline Mexico & 351 & 312 & 279 & 275 & 242 & 247 & -29.6 \\
\hline \multicolumn{8}{|c|}{ HS 62. Prendas de vestir y accesorios, no tejidos etc. } \\
\hline China & 4,167 & 4,153 & 4,479 & 5,490 & 6,618 & 10,231 & 145.5 \\
\hline Mexico & 5,119 & 4,672 & 4,504 & 4,170 & 4,137 & 3,842 & -25.0 \\
\hline \multicolumn{8}{|c|}{ HS 39. Plasticos y articulos de plastico } \\
\hline China & 2,915 & 3,228 & 3,766 & 4,280 & 5,195 & 6,639 & 127.8 \\
\hline Mexico & 1,185 & 1,240 & 1,332 & 1,465 & 1,978 & 2,433 & 105.3 \\
\hline \multicolumn{8}{|c|}{ HS 61. Prendas de vestir y accesorios, tejidos } \\
\hline China & 2,035 & 2,277 & 2,619 & 3,198 & 4,103 & 6,577 & 223.3 \\
\hline Mexico & 3,499 & 3,356 & 3,135 & 2,928 & 2,708 & 2,389 & -31.7 \\
\hline \multicolumn{8}{|c|}{ HS 42. arte en piel, saddlery, etc; bolsas de mano etc; gut art } \\
\hline China & 3,837 & 3,909 & 4,464 & 5,048 & 5,719 & 6,259 & 63.1 \\
\hline Mexico & 220 & 166 & 155 & 129 & 128 & 110 & -50.0 \\
\hline \multicolumn{8}{|c|}{ HS 73. Articulos de hierro o acero } \\
\hline China & 1,882 & 2,109 & 2,535 & 3,201 & 4,613 & 6,197 & 229.2 \\
\hline Mexico & 1,587 & 1,545 & 1,699 & 1,743 & 2,077 & 2,367 & 49.1 \\
\hline \multicolumn{8}{|c|}{ HS 87. Vehiculos, excepto trenes o tranvías, y sus partes, etc. } \\
\hline China & 1,949 & 1,545 & 1,946 & 2,464 & 3,384 & 4,208 & 115.9 \\
\hline Mexico & 26,026 & 26,277 & 26,358 & 25,392 & 26,143 & 26,814 & 3.0 \\
\hline \multicolumn{8}{|c|}{ HS 90. Opticos, Fotograficos, etc; instrumentos medicos o quirurgicos, etc; } \\
\hline China & 2,817 & 2,759 & 2,760 & 3,244 & 3,784 & 4,126 & 46.5 \\
\hline Mexico & 4,446 & 4,696 & 5,344 & 5,983 & 6,041 & 6,359 & 43.0 \\
\hline \multicolumn{8}{|c|}{ HS 63. Otros artículos de tela; paquetes; ropa y textiles usados; trapos } \\
\hline China & 1,101 & 1,204 & 1,650 & 2,360 & 3,061 & 3,970 & 260.6 \\
\hline Mexico & 684 & 666 & 733 & 713 & 722 & 723 & 5.7 \\
\hline \multicolumn{8}{|c|}{ HS 44. Madera y articulos de madera, carbon vegetal } \\
\hline China & 752 & 842 & 1,061 & 1,277 & 1,833 & 2,320 & 208.6 \\
\hline Mexico & 684 & 666 & 733 & 713 & 722 & 723 & 5.7 \\
\hline \multicolumn{8}{|c|}{ HS 83. Varios articulos de base de metal } \\
\hline China & 856 & 988 & 1,279 & 1,443 & 1,855 & 2,296 & 168.2 \\
\hline Mexico & 802 & 814 & 933 & 978 & 1,146 & 1,409 & 75.6 \\
\hline
\end{tabular}




\section{Análisis}

\begin{tabular}{|c|c|c|c|c|c|c|c|}
\hline China & 752 & 870 & 1,206 & 1,462 & 1,806 & 2,205 & 193.2 \\
\hline Mexico & 508 & 489 & 635 & 706 & 1,054 & 1,464 & 188.0 \\
\hline HS 99 & e legisla & oral; de & dad cor & nes de & comerc & & \\
\hline China & 759 & 784 & 957 & 1,230 & 1,652 & 2,069 & 172.4 \\
\hline Mexico & 1,524 & 1,492 & 1,512 & 1,558 & 1,776 & 1,945 & 27.6 \\
\hline HS 40. & Iule & & & & & & \\
\hline China & 470 & 486 & 680 & 873 & 1,256 & 1,899 & 304.0 \\
\hline Mexico & 587 & 541 & 609 & 690 & 834 & 945 & 61.1 \\
\hline HS 96. & urados v & & & & & & \\
\hline China & 749 & 849 & 924 & 1,037 & 1,219 & 1,423 & 89.9 \\
\hline Mexico & 238 & 285 & 350 & 363 & 451 & 459 & 93.0 \\
\hline
\end{tabular}

Fuente: U.S. Department of Commerce, Tradestats Express National Trade Data (http://tse.export.gov)

(16/01/07).

dos, en los últimos años las exportaciones de China se han incrementado significativamente. Mientras en 2001, China vendía a Estados Unidos frutas por 111.7 millones de dólares, en 2005 alcanzaron los 418.9 millones de dólares; y las hortalizas, que en 2001 sumaron 388.0 millones de dólares, en 2005 alcanzaron los 1,001.2 millones de dólares.
El resultado de la mayor interrelación comercial entre China y Estados Unidos se debe a los factores que se enumeran a continuación.

El acuerdo comercial China-Estados Unidos firmado en 1999 estableció las condiciones básicas para el acceso de un amplio rango de productos estadounidenses al mercado chino por medio de la

\section{Cuadro 6}

Importaciones agrícolas de Estados Unidos desde México, 2001-2005 (Miles de dólares)

\begin{tabular}{lrrrrr}
\hline & 2001 & 2002 & 2003 & 2004 & 2005 \\
\hline Total & $5,264,849$ & $5,518,072$ & $6,300,754$ & $7,262,370$ & $8,330,699$ \\
Granos & 200,411 & 220,707 & 263,676 & 305,372 & 331,498 \\
Oleaginosas & 41,568 & 36,851 & 41,252 & 48,874 & 67,962 \\
Frutas & 827,035 & 854,916 & 949,231 & $1,137,717$ & $1,504,055$ \\
Hortalizas & $3,928,587$ & $4,151,795$ & $4,726,622$ & $5,440,431$ & $6,218,937$ \\
\hline
\end{tabular}

Fuente: Department of Commerce, U.S. Census Bureau, Foreign Trade Statistics (24/01/07).

\section{Cuadro 7}

Exportaciones agricolas de Estados Unidos a México (Miles de dólares)

\begin{tabular}{lrrrrr}
\hline & 2001 & 2002 & 2003 & 2004 & 2005 \\
\hline Total & $7,407,255$ & $7,238,323$ & $7,890,545$ & $8,509,537$ & $9,429,404$ \\
Granos & $2,027,895$ & $2,009,263$ & $2,166,178$ & $2,362,193$ & $2,374,718$ \\
Oleaginosas & $1,103,711$ & $1,256,781$ & $1,496,536$ & $1,460,530$ & $1,634,089$ \\
Frutas & 282,510 & 270,328 & 256,896 & 244,747 & 309,797 \\
Hortalizas & $1,055,117$ & $1,046,361$ & $1,157,864$ & $1,255,779$ & $1,484,057$ \\
\hline
\end{tabular}

Fuente: Department of Commerce, U.S. Census Bureau, Foreign Trade Statistics (24/01/07). 
Cuadro 8

Importaciones agrícolas de Estados Unidos desde China, 2001-2005

(Miles de dólares)

\begin{tabular}{lccccr}
\hline & 2001 & 2002 & 2003 & 2004 & 2005 \\
\hline Total & 816,238 & $1,001,695$ & $1,287,600$ & $1,615,150$ & $1,871,829$ \\
Granos & 54,213 & 64,281 & 106,929 & 120,101 & 163,712 \\
Oleaginosas & 12,766 & 18,929 & 24,914 & 37,284 & 53,800 \\
Frutas & 111,710 & 162,144 & 264,889 & 356,670 & 418,821 \\
Hortalizas & 388,045 & 505,079 & 659,331 & 865,288 & $1,001,157$ \\
\hline
\end{tabular}

Fuente: Department of Commerce, U.S. Census Bureau, Foreign Trade Statistics (24/01/07).

Cuadro 9

Exportaciones agrícolas de Estados Unidos a China

\begin{tabular}{lccccc}
\hline & 2,001 & 2,002 & 2,003 & 2,004 & 2,005 \\
\hline Total & $1,938,690$ & $2,067,762$ & $5,016,684$ & $5,542,444$ & $5,233,180$ \\
Granos & 48,295 & 59,669 & 82,005 & 532,744 & 132,731 \\
Oleaginosas & $1,038,885$ & $1,026,712$ & $3,005,024$ & $2,378,546$ & $2,275,706$ \\
Frutas & 33,937 & 35,873 & 52,449 & 65,711 & 109,143 \\
Hortalizas & 161,487 & 171,378 & 296,443 & 355,390 & 314,000 \\
\hline
\end{tabular}

* A lo largo del este lustro el $97.4 \%$ de las oleaginosas correspondió a soya.

Fuente: Department of Commerce, U.S. Census Bureau, Foreign Trade Statistics (24/01/07).

eliminación de barreras arancelarias y la disminución de las tarifas arancelarias, incluyendo las de los productos agrícolas. De esta manera, el promedio general de las tarifas arancelarias bajó a 17\% y para los productos estadounidenses a $14.5 \%$ para 2004.

Asimismo, China estableció un sistema de cuota con tasa arancelaria (TRQ) a las importaciones de productos como trigo, maíz, algodón, cebada y arroz, el cual permite el acceso para comercializadores privados. Las reglas específicas del sistema de cuotas permiten también operar con mayor transparencia y aseguran que las importaciones chinas se efectúen de acuerdo con los compromisos adquiridos. Asimismo, los compromisos permiten el incremento anual en las cuotas de entre 1 a $3 \%$.

En el acuerdo bilateral de 1999 se estableció también el compromiso de permitir a las empresas estadounidenses la importación y distribución de algunos productos agrícolas sin la intermediación de las empresas comercializadoras estatales de China. Asimismo, China estuvo de acuerdo en eliminar las barreras sanitarias y fitosanitarias (SPS) que no estuvieran sustentadas en evidencias científicas, así como evitar los subsidios a las exportaciones de productos agrícolas.

Estos acuerdos iniciales establecidos entre China y Estados Unidos se han ido reglamentando también en otros instrumentos legales, como los establecidos con la Organización Mundial de Comercio.

\section{Conclusiones}

El ascenso de la relación comercial entre China y Estados Unidos constituye un fenómeno natural del desarrollo capitalis- 
ta. La rápida penetración de los productos chinos en los mercados internacionales y en especial en el de Estados Unidos, no se debe sólo a la mano de obra barata y explotada o a las prácticas desleales del comercio chino, sino a la serie de transformaciones políticas y económicas que se han dado en el sistema internacional a partir del decenio de los setenta, así como a las profundas transformaciones internas de China, al haber impulsado un modelo desarrollista y orientado su economía hacia el exterior, con un alto grado de pragmatismo.

El aislamiento de China desde los años cincuenta y hasta principios de los setenta, así como su posterior proceso de apertura del que ahora somos testigos, responden a estrategias que van más allá de los intereses económicos, aunque éstos están incluidos. Obedecen a razones de carácter político (incluyendo razones estratégico-militares).

Es en este contexto que se ha dado la disminución de la preponderancia de los productos hechos en México dentro del mercado de Estados Unidos, los cuales en algunos rubros específicos han sido sustituidos por productos hechos en China, y en otros comparten el mercado de Estados Unidos.

Los productos que ahora inundan los mercados internacionales son elaborados y comercializados por empresas extranjeras o empresas chinas asociadas con empresas foráneas, ya sean del Este de Asia o de otros continentes, que toman a China como plataforma de producción para acceder a los mercados globales.

El ingreso de China a la OMC creó las condiciones para el aumento de las exportaciones de productos chinos a Estados Unidos. Ello provocó que en algunos sectores industriales el incremento de las exportaciones chinas se diera a costa de las exportaciones mexicanas; en especial en sectores con un gran componente de mano de obra, tales como juguetes, juegos, equipo deportivo, calzado y prendas de vestir; mientras los productos hechos en china vieron aumentada drásticamente su participación en el mercado de EUA, los productos mexicanos redujeron su parte de este mercado. En muchos otros productos los bienes hechos en México y en China comparten el mercado de Estados Unidos. Sin embargo, en todos los casos el incremento de las exportaciones chinas ha sido superior a las exportaciones mexicanas a ese mercado. De este modo, no obstante que las exportaciones mexicanas continúan incrementando su participación en el mercado de EUA, al mismo tiempo han visto reducido su peso específico frente a los bienes manufacturados en China; específicamente desde 2003, en que China superó en términos globales su participación en el mercado estadounidense.

$\mathrm{Al}$ analizar las exportaciones de ambos países a Estados Unidos, se puede apreciar que México y China disponen, simultáneamente, de sectores competitivos y complementarios en el abordaje de ese mercado. El punto está en que el desarrollo industrial, la inversión en investigación y desarrollo, así como la inversión extranjera directa en industrias intensivas en capital está llevando a China a competir en estos sectores, donde México ha mantenido una 
ventaja relativa. Hasta ahora, con excepción de vehículos (HS 87) y ópticos, fotográficos, instrumentos médicos y quirúrgicos (HS 90), en los cuales las exportaciones mexicanas son superiores, en el resto los productos chinos han superado a los mexicanos, y aun en éstos, donde México mantiene una ventaja dentro del mercado estadounidense, las tasas de crecimiento en las exportaciones son mayores las de China que las de México.

La situación actual y futura de los mercados internacionales, y en especial el de Estados Unidos, requiere de una estrategia nacional para competir eficientemente, dada la participación cada vez más activa de los productores y comercializadores de países como China, India, Indonesia o Filipinas, por mencionar sólo algunos de los países asiáticos más competitivos para la economía de México. La situación impone el diseño de alianzas estratégicas con uno o varios países de las regiones de Asia y América, para trabajar conjuntamente en el abastecimiento de los mercados de estos países, así como competir en los mercados de otras regiones del planeta. me

\section{Notas}

1. De hecho, la planta productiva de China se compone de empresas de capital chino (público y privado), empresas conjuntas chino-extranjeras, y empresas cien por ciento de capital foráneo.

2. El Coordinating Committee for Multilateral Exports Controls (Cocom) fue establecido en 1947 durante la Guerra Fría para establecer un embargo a los países orientales por parte de los países occidentales. El Cocom tuvo 17 países miembro: Australia, Bélgica, Canadá, Dinamarca, Francia, Alemania, Grecia, Italia, Japón, Luxemburgo, Holanda, Noruega, Portugal, España, Turquía y Estados Unidos. Adicionalmente había otros países que cooperaban con esta política, tales como Austria, Finlandia, Irlanda, Nueva Zelanda, Suecia y Suiza. El Cocom cesó sus funciones el 31 de marzo de 1994 y entonces la lista de bienes embargados fue mantenida por cada una de los países miembros en lo particular. Véase: http:// encyclopedia.thefreedictionary.com/Cocom.

3. De hecho, en 1948 China había sido uno de los 23 países fundadores del Acuerdo General de Aranceles y Comercio (GATT), predecesor de la OMC, pero perdió su membresía en 1950.

4. Estados Unidos considera que cierto tipo de tecnología puede sea empleada con fines militares y que puede ser transferida a manos no deseadas. Con la India, por ejemplo, a finales de 2006 firmó un acuerdo por el cual permite este tipo de envíos y compromete a los indios a usarla solamente con fines civiles. Véase The China Business Forum, 2007.

\section{Referencias bibliográficas}

Feuerweker, Albert (2002) The Chinese Economy. Ann Arbor: University of Michigan Press.

Hernández, Roberto (2003a) "El comercio de granos básicos entre China y Estados Unidos; implicaciones para México", México y la Cuenca del Pacífico, vol. 6, núm. 18.

(2003b) "El comercio exterior de China a principios del siglo XXI", México y la Cuenca del Pacífico, vol. 6, núm. 20.

The China Business Forum (2005a) US-China Trade in Perspective: Asia's Emerging Union and Implications for the United States, junio. China: The USChina Business Council.

_ (2005b) "Made in U.S., Shunned in China", New York Times, noviembre 18.

- (2005c) "China's agricultural trade deficit against U.S. jumps 1.5 times in four years", People's Daily Online, http://english.peopledaily.com.cn. Consultado el 24 de enero de 2007.

_ (2007) "China hace fuerza para reducir su superávit comercial con EEUU", New York Times, 18 de mayo. http://www.adnmundo.com/contenidos/ comercio/china_eeuu comercio_exportaciones_ deficit_ce_180507.html.

USDA Foreign Āgricultural Service (FAS) (2005) "Remarks for Ellen Terpstra. 2005 United Produce Expo and Conference Rising Powers: China, India, and Brazil-Panel Discussion, Chicago, Illinois, abril, 30, 2005", USDA Foreign Agricultural Service (FAS) Communication to Congress. http://www.fas.usda. gov/info/speeches/ep043005.asp. Consultado el 26 de enero de 2007.

Yang, Jiawen (1992) China Today: Foreign Trade, vol. 2. Beijing: Dangdai Zhongguo Press.

_ (2004) "Sino-U.S. Trade Relations", The GW Center for the Study of Globalization. Washington: The George Washington University.

Zhang, Shu Guang (2001) Economic Cold War: America' Embargo against China and the SinoSoviet Alliance, 1949-1963. Palo Alto, California: Stanford University Press.

MÉXICO YLACUENCADELPACÍFICO vol. 9, núm. 27 / enero - diciembre de 2006 